\title{
Assessment of Different Clinical Variables Associated with Group A Streptococcal Throat Infection among Children in Primary Care Practice
}

\author{
Shereen N. Elboray ${ }^{1}$, Paul Little ${ }^{2}$, Nehal M. El-Raggal ${ }^{3}$, Diaa Marzouk ${ }^{4}$, Reda M. \\ Sabra $^{5}$, Sherin A. El Masry ${ }^{6}$ \\ ${ }^{1}$ Family Medicine, Faculty of Medicine, Ain Shams University; ${ }^{2}$ Primary Care, Faculty of \\ Medicine, Southampton University, UK; ${ }^{3}$ Pediatrics, Faculty of Medicine, Ain Shams \\ University; ${ }^{4}$ Public Health and Head of Family Medicine Department, Faculty of \\ Medicine, Ain Shams University; ${ }^{5}$ Otorhinolaryngology, Faculty of Medicine, Ain Shams \\ University; ${ }^{6}$ Clinical Pathology, Faculty of Medicine, Ain Shams University.
}

Received: October, 2017 Accepted: December, 2017

\begin{abstract}
Background: Group A streptococcus (GAS) is a major cause of morbidity and mortality worldwide. An effective targeting strategy is needed for appropriate antibiotic prescriptions for GAS sore throat. Objective: This study aimed to assess different clinical variables that can guide management of acute sore throat in children. Methods: A diagnostic cross-sectional study was conducted on 225 children, aged $\geq 3$ years, with acute sore throat attending two primary care clinics in Cairo, Egypt. Demographic information, clinical data and throat swabs were collected from the patients after consent from the parents. Results: The mean age of the children was 5.8 years and almost half of them were males, and had on average 3 attacks of sore throat per year. Out of the 225 children $64(28.4 \%)$ had positive GAS cultures and $183(81.3 \%)$ received antibiotics. Of the 183 who received antibiotics, $128(69.9 \%)$ had cultures negative for group A Streptococcus. There was little difference between those with and without GAS for commonly assessed clinical variables such as the absence of cough. The absence of skin rash was the only variable that was statistically significant $(92 \%$ and $98 \%$ respectively, $\mathrm{p}<0.05)$ Conclusion: Clinical variables associated with acute sore throat in Egyptian children cannot accurately diagnose GAS throat infection.
\end{abstract}

Key words: Primary Care - Acute sore throat-Group A streptococcus- children. Corresponding author: Dr. Shereen Elboray. E-mail: dr_shereennabil@yahoo.com

\section{Introduction}

Acute sore throat (pharyngitis) is a common symptom that occurs as a result of an inflammation of the pharynx, nasopharynx or tonsils (Pelucchi et al., 2012). Of the bacterial causes of sore throat, group A $\beta$-haemolytic streptococcus (GAS) also known as Streptococcus pyogenes (S. pyogenes), belongs to Lancefield serogroup A, and is the most frequently identified (5$36 \%){ }^{1,2}$ GAS accounts for $20 \%$ to $40 \%$ of sore throat cases in children and 5\% to $15 \%$ in adults. ${ }^{3,4,5}$ The global prevalence of GAS infections is at least 18.1 million cases, with an annual increase of 1.78 million new cases, with more significant burden in developing countries. ${ }^{6}$ In Egypt, the prevalence is $33 \%$ among 5-12 years age group and $24 \%$ in children less than 5 years old. ${ }^{7}$ Although GAS pharyngitis is a superficial infection in the throat, it can

$\begin{array}{llll}\text { Vol. } 36 & \text { No. } 3 & \text { July } & 2018\end{array}$


lead to various types of suppurative and non- suppurative complication. The suppurative sequelae include occurrence of peritonsillar cellulitis abscess (quinsy), retropharyngeal abscess or spread of the infection to nearby structures e.g cervical lymphadenitis, sinusitis, acute otitis media and mastoiditis. ${ }^{8}$ On the other hand, the nonsuppurative post-streptococcal diseases occur as an autoimmune inflammatory response to GAS infection and affect mainly the heart and the kidney leading to acute rheumatic fever (ARF) and acute glomerulonephritis. ${ }^{9}$ ARF follows untreated or inadequately treated GAS throat infection. ${ }^{10}$ The incidence of acute rheumatic fever in children aged 5-14 years is 336500 cases per year, $95 \%$ of them occur in less developed countries. ${ }^{6}$ Appropriate antibiotic treatment can reduce the risk of suppurative and non suppurative complications especially acute rheumatic fever ${ }^{11,12}$, however, the presumptive use of antibiotic therapy without accurate diagnosis of GAS throat infection contributes to the growing problem of antibiotic resistance. Diagnosis of GAS sore throat based on the clinical findings remains important ${ }^{13}$, and the issue of which symptoms and signs most strongly help diagnosing streptococcal infections is still debated. This study aimed to assess different clinical variables that can guide management of acute sore throat in children.

The goal of this study is to improve clinical practice by understanding how to target antibiotics for the treatment of children with GAS sore throat.

The main objective is to assess different clinical variables associated with acute sore throat in order to find out how well history and clinical examination performs in diagnosing group A betahemolytic streptococcal (GAS) in children with acute sore throat, attending primary care clinics in Cairo, Egypt.

\section{Methods:}

A diagnostic observational cross sectional study was carried out at two Family Medicine Clinics in Cairo: one located in Ain Shams Pediatric Hospital and the second was at Saraya El-kobba Family Health Center.. 225 children aged $\geq 3$ years presenting with acute sore throat during the period from October 2015 to June 2016 were recruited based on the following criteria: Inclusion criteria: children (boys and girls) aged $\geq$ 3 years with acute sore throat for $\leq 2$ weeks and abnormal looking throat (erythema and/ or pus and anterior cervical gland). Exclusion criteria: patients with non infective causes of sore throat; antibiotic use prior to consultation; and those with rheumatic fever or rheumatic heart disease. The sample size of 225 was determined based on the disease prevalence which was assumed to be $0.35^{6}$ and the assumption that multiple regression could be used if significant predictors variables were found; we assumed that the number of cases should be at least 15 cases per one predictor variable to avoid the problem of over fitting. As the largest equation would include 5 variables a sample of 225 children with 75 expected was proposed. Data were collected using clinical data sheet and throat swabs for culture. The clinical sheet included the following items: 1- Socio-demographic information (age, sex, parents' education, etc.); 2-General symptoms and signs associated with sore throat such as, difficult swallowing, fever, skin rash, cough, conjunctivitis, headache, muscleache, abdominal pain, diarrhea, nausea, vomiting, etc.; and 3- Local signs on throat examination such as, tonsillar exudate, tonsillar inflammation, congestion of the pharynx, enlarged 
tender anterior cervical lymph node...etc. Throat swabs were taken from each patient in the clinic using sterile cotton tipped swabs then samples were sent within maximum 2 hours to the central laboratory in Ain Shams University Hospital for bacteriological cultures. Diagnosis of GAs was done by detection of the pathogen by means of microscopy using gram stain and culturing on blood agar plate Data management and analysis were done using SPSS (Statistical Package for Social Science) software version 24.0. Chi square and Fisher Exact tests were used for categorical variables while student t- test was used for continuous data. The significance of significance was set at 0.05 .

Ethical Consideration: Administrative and Faculty of Medicine, Ain Shams University Ethical committee board approvals were obtained to carry out the study in the Family Medicine Clinics. Informed consents were taken from children's parents or guardians. (No: FWA 000017585)

\section{Results}

I- Description of socio-demographic characteristics of study population: One hundred ninety-nine children (88.4\%) were recruited in the study from Saraya El-Kobba Family Medicine Center. The mean of children age was 5.8 years. Almost half of the study sample were males $(50.7 \%)$. Group A streptococcus (GAS) was detected in 64 patients (28.4\%; 95\% CI [22.7\% - 34.7\%]. Out of 225 children, $183(81.3 \%)$ received antibiotics (Table 1).Thirty six $(56.2 \%)$ of children who tested positive for GAS were $\leq 5$ years old and $45.3 \%$ of them were males. (Table2). Of the 183 who received antibiotics, $128(69.9 \%)$ had culture-negative results for group A Streptococcus, and $61.7 \%$ were $\leq 5$ years old (Table 3). There was no statistically significant difference between both streptococcal positive and negative groups as regards their age, gender and antibiotic therapy. The frequency and social impact of sore throat attacks on Children are illustrated in table 4. The mean \pm SD of the number of acute sore throat attacks experienced by children per year was $3.1 \pm 1.25$. Also the mean \pm SD of the timing of the last attack of sore throat was 2.2 months \pm 1.50 . Out of 225 children, 99 (44\%) suffered from sleep disturbance due to the illness and $38.7 \%$ had to be absent from the attended school or nursery. There was no statistically significant difference between the positive and negative throat culture groups regarding the frequency of sore throat attacks or the social impact of attacks

II- Assessment of clinical parameters associated with sore throat in the study population:Out of the 64 children who had GAS throat infection, $54(84.4 \%)$ had attended rapidly to the primary care clinics within 3 days of the onset of their symptoms and almost half of the children had difficulty swallowing (51.6\%). The absence of 'viral' symptoms such as conjunctivitis (91.9\%) and skin rash $(98.1 \%)$ were more in the culture negative group. Herpetic rash and chickenpox rash were the only types of skin rash detected among the children with sore throat. Although $81.3 \%$ of the positive group had fever, only $42.2 \%$ had a history of high temperature $>38^{\circ} \mathrm{c}$. Other symptoms that the patients had during their consultation, including muscle-ache, headache and GIT symptoms (abdominal pain , diarrhoea, nausea and vomiting) were less prevalent in the GAS positive group, ranging from $7.8 \%$ to $42.2 \%$. There was no statistically significant difference between the positive and negative culture groups as regard any of these clinical parameters 
Table (1): Characteristics of children with acute sore throat attending Primary Care Clinics from October 2015- June $2016(n=225)$.

\begin{tabular}{|l|c|}
\hline \multicolumn{1}{|c|}{ Characteristics } & Total \\
\hline Age (y): Mean ( Min- Max) & $5.8(3-14)$ \\
\hline Male: N (\%) & $114(50.7)$ \\
\hline $\begin{array}{l}\text { Percentage of children with GAS } \\
\text { culture positive: N (\%) }\end{array}$ & $64(28.4)$ \\
\hline Antibiotics prescription: N (\%) & $183(81.3)$ \\
\hline
\end{tabular}

Table (2): Percentage of patients with sore throat who tested positive or negative by throat culture based on their age and gender.

\begin{tabular}{|c|c|c|c|c|}
\hline \multirow[b]{2}{*}{$\begin{array}{l}\text { Children age } \\
\text { and gender }\end{array}$} & \multicolumn{2}{|c|}{$\begin{array}{l}\text { Streptococcal positive and - } \\
\text { negative groups }(n=225)\end{array}$} & \multirow[b]{2}{*}{ Total } & \multirow[b]{2}{*}{$P$ value } \\
\hline & $\begin{array}{c}\text { GAS Positive } \\
(n=64) \\
\mathbf{N}(\%)\end{array}$ & $\begin{array}{c}\text { GAS Negative } \\
(\mathbf{n}=\mathbf{1 6 1}) \\
\mathbf{N}(\%)\end{array}$ & & \\
\hline$\leq 5$ years old & $36(56.2)$ & $99(61.5)$ & $135(60.0)$ & \multirow{2}{*}{$\begin{array}{l}\mathbf{x}^{2}=0.524 \\
\mathbf{p}=0.469\end{array}$} \\
\hline$>5$ years old & $28 \quad(43.8)$ & $62(38.5)$ & $90(40.0)$ & \\
\hline Male & $29(45.3)$ & $85(52.8)$ & $104(50.5)$ & \multirow{2}{*}{$\begin{array}{l}\mathbf{x}^{2}=1.026 \\
\mathbf{p}=0.311\end{array}$} \\
\hline Female & $35(54.7)$ & $76(47.2)$ & $102(49.5)$ & \\
\hline
\end{tabular}

$$
\mathbf{x}^{2} \text { Chi-Square Test }
$$

Table (3): Percentage of children with sore throat who received antibiotics prescription in relation to culture results and age $(n=225)$.

\begin{tabular}{|c|c|c|c|c|c|c|}
\hline \multirow[b]{2}{*}{ Management plan } & \multicolumn{2}{|c|}{ Type of the organisms } & \multirow[b]{2}{*}{ Sig. * } & \multicolumn{2}{|c|}{ Age } & \multirow[b]{2}{*}{ Sig. * } \\
\hline & $\begin{array}{c}\text { GAS +ve } \\
\mathbf{n}=\mathbf{6 4} \\
\mathrm{N}(\%)\end{array}$ & $\begin{array}{c}\text { GAS -ve } \\
\text { n=161 } \\
\mathrm{N}(\%)\end{array}$ & & $\begin{array}{c}\leq \mathbf{5} \text { years } \\
\text { old } \\
\mathrm{N}(\%)\end{array}$ & $\begin{array}{c}>5 \text { years } \\
\text { old } \\
N(\%)\end{array}$ & \\
\hline $\begin{array}{l}\text { Children who received } \\
\text { Antibiotic } n=183\end{array}$ & $55(30.1)$ & $128(69.9)$ & \multirow{2}{*}{0.264} & $113(61.7)$ & $70(38.3)$ & \multirow[b]{2}{*}{0.264} \\
\hline $\begin{array}{l}\text { Children who did not } \\
\text { receive antibiotics } n=42\end{array}$ & $9(21.4)$ & $33(78.6)$ & & $22(52.4)$ & $20(47.6)$ & \\
\hline
\end{tabular}

$$
\text { (\%) of the row. } \quad * \text { Chi- Square Test }
$$


Table(4): Frequency and social impact of acute attacks of sore throat in Children.

\begin{tabular}{|c|c|c|c|c|}
\hline \multirow[b]{2}{*}{ Variables } & \multicolumn{2}{|c|}{ Throat culture results } & \multirow{2}{*}{$\begin{array}{c}\text { Total } \\
(n=225)\end{array}$} & \multirow[b]{2}{*}{ Sig } \\
\hline & $\begin{array}{c}\text { GAS +ve } \\
(n=64)\end{array}$ & $\begin{array}{c}\text { GAS -ve } \\
(n=161)\end{array}$ & & \\
\hline $\begin{array}{l}\text { Frequency of Acute sore } \\
\text { throat attacks/ year } \\
(n=221) \\
\text { Mean } \pm \text { SD }\end{array}$ & $3.2 \pm 1.24$ & $3.1 \pm 1.26$ & $3.1 \pm 1.25$ & $\begin{array}{l}\mathbf{t}=0.580 \\
\mathbf{p}=0.563\end{array}$ \\
\hline $\begin{array}{l}\text { Time since last attack in } \\
\text { months }(n=220) \\
\text { Mean } \pm S D\end{array}$ & $2.4 \pm 1.6$ & $2.1 \pm 1.45$ & $2.2 \pm 1.50$ & $\begin{array}{l}\mathbf{t}=1.298 \\
\mathbf{p}=0.196\end{array}$ \\
\hline $\begin{array}{l}\text { Sleep disturbance } \\
\mathrm{n}(\%)^{*}\end{array}$ & $33(51.6 \%)$ & $66(41 \%)$ & $99(44 \%)$ & $\begin{array}{l}\mathbf{x}^{2}=2.076 \\
\mathbf{p}=0.150\end{array}$ \\
\hline $\begin{array}{l}\text { Interference with normal } \\
\text { activity } * * \mathrm{~N}(\%)^{*}\end{array}$ & $23(35.9 \%)$ & $64(39.8 \%)$ & $87(38.7 \%)$ & $\begin{array}{l}\mathbf{x}^{2}=0.281 \\
p=0.596\end{array}$ \\
\hline
\end{tabular}

* (\%) of the column

(t) independent sample t-test
**This included absence from school or nursery. $\left(\mathbf{x}^{2}\right)$ Chi- Square Test

Table (5): Clinical characteristics of children with sore throat based on the culture status.

\begin{tabular}{|c|c|c|c|c|}
\hline \multirow[t]{2}{*}{ Characteristics } & \multicolumn{2}{|c|}{ Throat culture results $(\mathrm{n}=\mathbf{2 2 5})$} & \multirow{2}{*}{$\begin{array}{l}\text { Total } \\
\text { n }(\%)\end{array}$} & \multirow[t]{2}{*}{ p-value } \\
\hline & GAS+ve(n=64) & GAS -ve (n=161) & & \\
\hline Attended rapidly & $54(84.4 \%)$ & $127(78.9 \%)$ & $181(80.4)$ & 0.350 \\
\hline Difficulty swallowing & $33(51.6 \%)$ & $91(56.5 \%)$ & $124(55.1)$ & 0.50 \\
\hline No Cough & $16(25.0 \%)$ & $32(19.9 \%)$ & $48(14.3)$ & 0.398 \\
\hline No Coryza (Rhinitis) & $29(45.3 \%)$ & $59(36.6 \%)$ & $88(39.1)$ & 0.230 \\
\hline No Conjunctivitis & $58(90.6 \%)$ & $148(91.9 \%)$ & $206(91.6)$ & 0.752 \\
\hline No Skin rash & $59(92.2 \%)$ & $158(98.1 \%)$ & $217(96.4)$ & $0.040 *$ \\
\hline $\begin{array}{l}\text { Fever in the previous } \\
24 \text { hours }\end{array}$ & $52(81.3 \%)$ & $111(68.9 \%)$ & $163(72.4)$ & 0.062 \\
\hline $\begin{array}{l}\text { History of } \\
\text { temperature }>38^{\circ} \mathrm{C}\end{array}$ & $27(42.2 \%)$ & $54(33.5 \%)$ & $81(36)$ & 0.224 \\
\hline Muscle-ache $(\mathrm{n}=167)$ & $9 / 44(20.5 \%)$ & $29 / 123(23.6 \%)$ & $38(22.8)$ & 0.672 \\
\hline Headache $(n=137)$ & $17 / 47(36.2 \%)$ & $44 / 126(34.9 \%)$ & $61(27.1)$ & 0.878 \\
\hline Abdominal Pain & $27(42.2 \%)$ & $60(37.3 \%)$ & $87(38.7)$ & 0.494 \\
\hline Diarrhea & $5(7.8 \%)$ & $12(7.5 \%)$ & $17(7.6)$ & 0.927 \\
\hline
\end{tabular}

\begin{tabular}{lllll}
\hline The Egyptian Journal of Community Medicine & Vol. 36 & No. 3 & July & 2018
\end{tabular} 


\begin{tabular}{|l|r|r|r|l|}
\hline Nausea $(\mathrm{n}=198)$ & $14 / 58(24.1 \%)$ & $30 / 140(21.1 \%)$ & $44(22.2)$ & 0.677 \\
\hline Vomiting & $15(23.4 \%)$ & $38(23.6 \%)$ & $53(23.6)$ & 0.979 \\
\hline
\end{tabular}

Table (6): Clinical findings on local examination of patients' throat.

\begin{tabular}{|c|c|c|c|c|}
\hline \multirow{2}{*}{$\begin{array}{l}\text { Local examination } \\
\text { findings } \mathrm{n}(\%)^{*}\end{array}$} & \multicolumn{2}{|c|}{ Throat culture results $(n=225)$} & \multirow{2}{*}{$\begin{array}{l}\text { Total } \\
\text { n }(\%)\end{array}$} & \multirow{2}{*}{$\begin{array}{c}\text { p- } \\
\text { value }\end{array}$} \\
\hline & $\begin{array}{c}\begin{array}{c}\text { GAS +ve } \\
(n=64)\end{array} \\
\end{array}$ & $\begin{array}{c}\text { GAS -ve } \\
(n=161)\end{array}$ & & \\
\hline Tonsillectomy & $2(3.1 \%)$ & $17(10.6 \%)$ & $19(8.4)$ & 0.089 \\
\hline $\begin{array}{l}\text { Tonsillar swelling } \\
(\mathrm{n}=206)\end{array}$ & $49 / 62(79.0 \%)$ & $117 / 144(81.3 \%)$ & $166(80.6)$ & 0.712 \\
\hline $\begin{array}{l}\text { Inflamed tonsils } \\
(\mathrm{n}=206)\end{array}$ & $60 / 62(96.8 \%)$ & $129 / 144(89.6 \%)$ & $189(91.7)$ & 0.104 \\
\hline $\begin{array}{l}\text { Tonsillar exudates } \\
(\mathrm{n}=206)\end{array}$ & $11 / 62(17.7 \%)$ & $27 / 144(18.8 \%)$ & $38(18.4 \%)$ & 0.864 \\
\hline $\begin{array}{l}\text { Congestion of the } \\
\text { pharynx }\end{array}$ & $44(68.8 \%)$ & $106(65.8 \%)$ & $150(66.7)$ & 0.676 \\
\hline $\begin{array}{l}\text { Petechiae on the } \\
\text { palate }\end{array}$ & $0(0.0 \%)$ & $2(1.2 \%)$ & $2(0.8)$ & $0.999 *$ \\
\hline $\begin{array}{l}\text { Ulcers (pharynx } \\
\text { or palate) }\end{array}$ & $0(0.0 \%)$ & $1(0.6 \%)$ & $1(0.4)$ & $1.000^{*}$ \\
\hline $\begin{array}{l}\text { Enlarged cervical } \\
\text { Lymph node }\end{array}$ & $30(46.9 \%)$ & $87(54.0 \%)$ & $117(52)$ & 0.333 \\
\hline
\end{tabular}

* Fisher Exact test

except for the skin rash $(\mathrm{p}<0.05)$ (Table $5)$.

On examination of patients' throats, 19 cases had tonsillectomy and only 2 of them had GAS positive culture. After excluding these 19 patients, analysis of other tonsillar signs were done. Tonsillar swelling and inflammation were common among the culture positive group, $79 \%$ and $96.8 \%$, respectively, however, only 11 cases had tonsillar exudates $(17.7 \%)$. Over $65 \%$ of the cases had congestion in the pharyngeal wall (44/64). Only 1 child had an ulcer and 2 children had petechiae on the palate, and all of them were negative for GAS throat culture. Approximately half of the GAS positive cases had an enlarged anterior cervical lymph nodes $(46.9 \%)$. There was no statistically significant differences in the clinical examination findings between the positive and negative throat culture groups (Table 6).

\section{Discussion}

Streptococcus pyogenes (GAS) is a significant human pathogen that may rarely cause life -threatening infections (Carapetis et al., 2005 \& Hugh et al., 
2013). Throat culture is considered the gold criterion for diagnosis of streptococcal pharyngitis, however laboratory based diagnosis is not feasible especially in regions with limited resources, where clinicians depend on their clinical experience and patients' presenting symptoms to make a decision about prescribing antibiotics. This study was designed to assess different clinical parameters that could be associated with GAS throat infection that could guide management of acute sore throat. A total number of 225 children with sore throat were recruited in the study. The mean age of the study population was 5.8 years, and $60 \%$ of them were $\leq 5$ years old and almost half were male. This corresponds with the findings from The Egyptian Study where the Steinhoff Score was derived ( mean age \pm SD was $5.9 \pm 2.4 ; 59 \%$ of the children $<6$ years old and $47 \%$ were male) (Steinhoff et al., 2005). There is little difference between males and females in GAS pharyngitis, so data are usually not displayed for gender (Steinhoff and Rimoin, 2004). The prevalence of GAS detected in our study was $28.4 \%$. This is comparable with $24.6 \%$ prevalence of GAS in Steinhoff et al., 2005 Study in Egypt and the figures in UK as the overall prevalence of GAS ranged from $22.5 \%$ to 27.7\% (Little et al., 2012\& Little et al., 2013). In Canada, the prevalence of GAS was even higher among children $(34.8 \%$ $37 \%$ ) (McIsaac et al., 1998 \& Fine et al., 2012). The prevalence of GAS in the current study is slightly different from other studies among children in Egypt. In 2002, GAS was found in $17 \%$ of the cases and 42.2\% in 2015(Bassili et al., 2002 \& Shereen Abd El-Ghany et al., 2015). These difference may be related to the changes that occur to the disease epidemiology with seasonal variation, environmental conditions, age group, socioeconomic conditions, and level of primary health care (Khaled Sorour, 2014). In our study, GAS prevalence was slightly higher among children aged $>5$ years $(28 / 90$ [31.1\%]); this is similar to the findings from the meta-analysis conducted to measure the prevalence of GAS among children where children $<5$ years old had lower rates of positive throat cultures results (Nader et al., 2010 and 2012). This can be related to the high level of transmission of organisms from one child to another during school age, 511 years (Steinhoff and Rimoin, 2004). In our study, the absence of rash was the most prevalent finding in $91.9 \%$ of the positive cases and absence of rhinitis among $46.8 \%$, while enlarged $\mathrm{LN}$ was less prevalent (46.8\%).Similarly, in Steinhoff et al Study 2005, the absence of skin rash was the most common variable among positive culture cases (94.0\%) and enlarged cervical LN was present in $81 \%$ of them, while absence of rhinitis (coryza) occurred in 52\%. Compared to the Little et al Study 2012, the presence of fever in the previous 24 hours among GAS positive group was similar to the present study at $80 \%$. Although purulent tonsils and absence of cough or coryza were more prevalent in Little et al Study 2012(more than 50\%), rapid attendance and inflamed tonsils were more common among our study group, $83.9 \%$ and $96.8 \%$, respectively. In addition, the absence of cough was significantly lower in our study $(25.8 \%)$ compared with $72 \%$ in a previous study (Fine et al., 2012). This difference in the presenting symptoms and sign in patients with acute sore throat may be due to the age of the population in each study; some studies investigated the clinical variables among both children and adults (Little et al, 2012 and Fine et al 2012), while the current study was conducted among children only. Symptoms and signs of streptococcal throat infection vary depending on patient age, timing of the 
illness and infection severity. Younger patients commonly develop gastrointestinal manifestations such as nausea, vomiting, and abdominal pain ( Zartash and Michelle,2016). In spite of the fact that no single clinical parameter in our study was statistically significant except for absence of skin rash, which can be related to the smaller study size, clinical manifestations of patients with acute sore throat remain universally the main guidance to clinicians in management of such cases especially in regions with limited resources.

\section{Conclusion \& Recommendation:}

Clinical variables associated with acute sore throat can not accurately diagnose GAS throat infection in primary care practice among children in Egypt, hence we recommend the following: Larger scale studies in different settings are needed to get a more reliable picture about variable symptoms and signs associated with GAS throat infection. National guidelines for sore throat management and primary prevention of rheumatic fever should be developed to account for the presumptive use of antibiotics in the current practice. The use of rapid streptococcal antigen tests should be assessed.

\section{References}

1. SIGN (Scottish Intercollegiate Guidelines Network), (2010). Management of sore throat and indications for tonsillectomy. A National clinical guideline 117. Available at: http://www.sign.ac.uk/pdf/sign117.pdf.

Accessed: 15.07.2017

2. Cohen JF, Cohen R and Chalumeau M (2013). Rapid antigen detection test for group A streptococcus in children with pharyngitis (Protocol). Cochrane Database of Systematic Reviews, Issue 4. Art. No.: CD010502. DOI: 10.1002/14651858.CD010502
3. Ebell MH (2014). Diagnosis of Streptococcal Pharyngitis. American Family Physician;89 (12):976-977

4. Shaikh N, Leonard E, Martin JM (2010). Prevalence of streptococcal pharyngitis and streptococcal carriage in children: a metaanalysis.Pediatrics;126(3):557-64.

5. Wessels MR (2011). Clinical practice. Streptococcal pharyngitis. New England Journal of Medicine;364(7):648-55

6. Carapetis JR, Steer AC, Mulholland EK, Weber M (2005). The global burden of group A streptococcal diseases. Lancet Infect Dis.;5(11):685-694

7. Nader Shaikh, Erica Leonard and Judith M. Martin. (2010). Prevalence of streptococcal phayrngitis and streptococcal carriage in children: A meta-analysis. Pediatrics; 126(3): e557564

8. Gerber MA and Shulman ST (2004). Rapid diagnosis of pharyngitis caused by group A streptococci. Clin Microbiol Rev ; 17:571-80

9. Smriti Chauhan, Nitin Kashyap, Anil Kanga, Kamlesh Thakur, Anuradha Sood, Lata Chandel (2016). Genetic Diversity among Group A Streptococcus Isolated from Throats of Healthy and Symptomatic Children Journal of Tropical Pediatrics; 62:152-157.

10. World Health Organization (WHO)(2011).Global atlas on cardiovascular disease prevention and control. Available at: http://www.who.int/cardiovascular_disea ses/publications/atlas_cvd/en/ Accessed 6th February 2017.

11. Spinks A, Glasziou PP, Del Mar CB (2013). Antibiotics for sore throat. Cochrane Database of Systematic Reviews , Issue 9. [DOI: 10.1002/14651858.CD000023.pub3] Retrieved from: http://onlinelibrary.wiley.com/doi/10.100 2/14651858.CD000023.pub4/pdf Accessed online on 15 July 2017 
12.Josep M. Cots, Juan-Ignacio Alos, Mario Barcena, Xavier Boleda, Jose L. Canada, etal., (2015). Recommendations for management of acute pharyngitis in adults. Acta Otorrinolaringologica; 66(3): 159-170 13.Dunne EM, Marshall J1, Baker CA, et al (2013). Detection of group a streptococcal pharyngitis by quantitative pcr. BMc infect dis. 2013;13: 312

14.Pelucchi C., Grigoryan L., Galeone C., Esposito S., Huovinen P., et al., (2012). Guideline for the management of acute sore throat. ESCMID Sore Throat Guideline Group. Clinical Microbiology and infection; 15 , supplement 1

15.Hugh D Allen, David J Driscoll, Robert E Shaddy, Timothy F Feltes (2013). Heart disease in infants, children and adolescents eighth edition- chapter 60 ( Rheumatic fever and rheumatic heart disease).Philadelphia: Lippnocott Williams Wilkins.

16.Steinhoff MC, Walker CF, Rimoin AW and Hamza HS (2005). A clinical decision rule for management of streptococcal pharyngitis in low-resource settings. Acta Paediatr ;94:1038-42

17. Steinhoff MC and Rimoin AW (2004). Epidemiology, clinical presentations, and diagnosis of streptococcal pharyngitis in developing countries of the world. In: Pachere JC, Kaplan EL, editors. Streptococcal pharyngitis optimal management. 3rd ed. Infect Dis. Basel, Karger; vol 3: 4965 (DOI: 10.1159/000076215).

18. Little P, Richard Hobbs FD, David Mant, Cliodna AM McNulty and Mark Mullee (2012). Incidence and clinical variables associated with streptococcal throat infections: a prospective diagnostic cohort study. British Journal of General Practice;e787-94

19.Little P, Moore M, Hobbs FD, Mant D, McNulty C, et al (2013). PRImary care Streptococcal Management (PRISM) study: identifying clinical variables associated with
Lancefield group A beta-haemolytic streptococci and Lancefield non-Group A streptococcal throat infections from two cohorts of patients presenting with an acute sore throat. BMJ ;3(10):e003943.

20.McIsaac WJ, White D, Tannenbaum D and Low DE (1998). A clinical score to reduce unnecessary antibiotic use in patients with sore throat. Can Med Assoc J;158:7583. 21.Fine AM., Nizet V. and Mandl KD. (2012). Large-Scale Validation of the Centor and McIsaac Scores to Predict Group A Streptococcal Pharyngitis. Aach Intern Med; 172(11): 847-852

22.Bassili A., Barakat S., Sawaf G., Zaher S, Zaki A, et al., (2002). Identification of clinical

criteria for group Abeta hemolytic streptococ cal pharyngitis in children living in a rheumatic fever endemic area. Journal of Tropical Pediatrics; 48 (5): 285-293

23. Shereen Mohamed Abd El-Ghany,a Abeer Ahmed Abdelmaksoud,a Sally Mohamed Saber,b Dalia Hosni Abd El Hamidb (2015). Group A beta-hemolytic streptococcal pharyngitis and carriage rate among Egyptian children: a case-control study. Ann Saudi Med; 35(5): 377-382

24. Khaled A. Sorour (2014). Rheumatic heart disease in Egypt: Gloomy past and promising future. The Egyptian Heart Journal ;66: 139-142

25.Nader Shaikh, , Nithya Swaminathan, and Emma G. Hooper (2012). Accuracy and Precision of the Signs and Symptoms of Streptococcal Pharyngitis in Children: A Systematic Review. The Kournal of Pediatrics; 160 (3): 487-93.

26. Zartash Zafar Khan and Michelle R Salvaggio (2016). Group Streptococcal Infections Clinical Presentation. Medscape. Available at: http://emedicine.medscape.com/article/22893 6-clinical Accessed on 17th July, 2017 